
ПРОТЕЗИРОВАНИЯ

\author{
Бараш A.H. (alissa.barash@mail.ru)
}

УО «Гомельский государственный медицинский университет», Гомель, Беларусь

Цель: оценить влияние глазного протезирования на качество жизни пациентов с анофтальмом и субатрофией глаза.

Материал и методы. В исследовании приняли участие 128 пацчентов, 75 мужчин и 53 женщины, средний возраст составил 59 [48; 70] лет. Средний возраст мужчин - 59 [51; 69] лет, женщин - 59 [46; 75] лет. Для оченки качества жизни пациентов после глазного протезирования использовался опросник «SF-36», валидизированный и адаптированный Межнациональнылм центром исследования качества жизни (МЦИКЖ, 2. Санкт-Петербург).

Результатыл. При исследовании качества жизни у пациентов после глазного протезирования и практически здоровых лиц выявлены низкие параметры качества жизни у пациентов после глазного протезирования как по интегральным показателям психического (SF36nз) и физического здоровья (SF36фз), так и по их составляюшим шкалам: физическое функционирование $\Phi \Phi(U=1620, p=0,04)$, ролевое функционирование, обусловленное физическим состоянием РФФ (U=1552, p=0,02), общее состояние здоровья O3 (U=1250, $p<0,0001)$, интенсивность боли Б $(U=1357, p=0,002)$, жизненная активность Ж $(U=1194, p=0,0001)$, nсихическое здоровье ПЗ (U=1398, $p=0,003)$.

Выводы. Полученные результать исследования подтверждают, что тяжелая офтальмопатология, приведшая к потере зрения и глаза как органа является тяжелой психологчческой и физической травмой для человека и снижает уровень общего состояния здоровья, при этом снижая качество жизни по всем сферам.

Ключевые слова: глазное протезирование, качество жизни, анофтальм, субатрофия глаза.

\begin{abstract}
Введение
Удаление глазного яблока (энуклеация, эвисцерация) - тяжелая психологическая и физическая травма для человека. Потеря зрения оказывает значительное негативное влияние на весь комплекс социального функционирования человека (личного, профессионального, семейно-бытового), затрудняя его последующую реадаптацию к повседневной жизни. Глазное протезирование как метод реабилитации пациентов с анофтальмом и субатрофией глазного яблока является обязательным, уменьшая психологическую травму, способствует быстрейшей реабилитации инвалидов с данной патологией. Основополагающим фактором, от которого зависит косметический эффект при глазном протезировании, является формирование качественной опорно-двигательной культи, создание которой после энуклеации/эвисцерации возможно только путем введения в полость глазницы имплантата. Своевременная и адекватная пластика глазницы после эвисцерации/энуклеации в сочетании с поэтапным глазным протезированием позволяет повысить социальную активность пациентов и качество их жизни (КЖ) [1-4].

Психологическая поддержка пациентов после глазного протезирования крайне необходима, так как повышение КЖ лиц с анофтальмом и слабовидящих - социальная проблема, касающаяся не только офтальмологов, но и лиц других медицинских специальностей, сферы образования, а также родственников и общества в целом [5-6].

Несовершенство глазного протезирования, неадекватное создание опорно-двигательной культи, отсутствие психологического консультирования способствуют формированию своего рода «комплекса неполноценности» у таких

людей. У данной категории лиц в значительной мере снижается КЖ, а это в свою очередь обуславливает необходимость всестороннего изучения медико-социальных последствий, возникающих после глазного протезирования. Оценка таких последствий и анализ клинико-социальных факторов, влияющих на КЖ лиц с данной патологией, будет способствовать совершенствованию медико-социальной реабилитации данной категории пациентов.

Цель: оценить влияние глазного протезирования на качество жизни пациентов с анофтальмом и субатрофией глаза.

\section{Материал и методы}

В исследовании приняли участие 128 пациентов после глазного протезирования, 75 мужчин и 53 женщины, средний возраст составил 59 [48; 70] лет. Средний возраст мужчин - 59 [51;69] лет, женщин - 59 [46; 75] лет.

Для оценки влияния глазного протезирования на КЖ пациентов вся выборка была разделена на четыре группы:

I группа - пациенты после удаления глазного яблока путем стандартной эвисцерации/энуклеации с формированием опорно-двигательной культи с использованием разных типов имплантатов и без таковой (85 пациентов); I группа была разделена на две подгруппы:

подгруппа а - пациенты после удаления глазного яблока путем стандартной эвисцерации/ энуклеации без использования орбитальных имплантатов (70 пациентов);

подгруппа б - пациенты после удаления глазного яблока путем эвисцерации/энуклеации с формированием опорно-двигательной культи с использованием орбитальных имплантатов (15 пациентов).
\end{abstract}


II группа - пациенты с субатрофией глазного яблока (21 пациент).

III группа - пациенты после удаления глазного яблока путем эвисцерации с формированием опорно-двигательной культи с использованием аллотрансплантата по разработанному методу (22 пациента) [7].

IV группа (контрольная группа) - практически здоровые лица без психической и тяжелой некомпенсированной соматической патологии (33 чел., из них 20 мужчин, 13 женщин; средний возраст мужчин - 57 [53; 65] лет, женщин - 64 [59; 68] года.

Для оценки КЖ пациентов после глазного протезирования использовался опросник «SF-36», валидизированный и адаптированный Межнациональным центром исследования качества жизни (МЦИКЖ г. Санкт-Петербург) в 1998 г. Опросник «SF-36» является одним из наиболее распространенных, применяется как в популяционных, так и специальных исследованиях многих стран мира. Опросник состоит из 36 пунктов, сгруппированных в восемь шкал: физическое функционирование, ролевое (физическое) функционирование, боль, общее здоровье, жизнеспособность, социальное функционирование, эмоциональное функционирование, психическое здоровье. Вышеперечисленные шкалы группируются в два показателя: «физический компонент здоровья» и «психологический компонент здоровья». Физический компонент здоровья включает физическое функционирование; ролевое функционирование, обусловленное физическим состоянием; интенсивность боли и общее состояние здоровья. Психологический компонент здоровья состоит из оценок психического здоровья; ролевого функционирования, обусловленного эмоциональным состоянием; социального функционирования и жизненной активности. Результаты представлены в виде оценок в баллах, составленных таким образом, что более высокая оценка указывает на более высокий уровень КЖ. Показатель 100 является максимальным и указывает на полное здоровье. Сбор данных осуществлялся путем анкетирования пациентов прямым способом.

На основании выполненных исследований создана компьютерная база данных в системе EXCEL-2017. Весь полученный материал подвергнут статистической обработке, проводившейся с использованием программы STATISTICA 10.0 (Stat Soft). Проверка нормальности распределения признаков проводилась с использованием критерия Шапиро-Уилка. Оценка нормальности распределения количественных признаков показала, что распределение показателей отличалось от нормального. Поэтому сравнительный анализ между группами проводился с использованием методов непараметрической статистики для проверки гипотезы об отсутствии различий в независимых группах по одному признаку: тест Mann-Whitney (U) для сравнения двух независимых выборок; критерий Wilcoxon (Z) для сравнения связанных выборок.
Данные представляли в виде Ме [25; 75], где Ме - медиана, 25 - 25-й процентиль и $75-75$-й процентиль. За уровень статистической значимости принималось значение $\mathrm{p}<0,05$.

\section{Результаты и обсуждение}

При исследовании выявлены низкие параметры КЖ у пациентов после глазного протезирования как по интегральным показателям психического (SF36пз) и физического здоровья (SF36фз), так и по их составляющим шкалам: физическое функционирование ФФ (U=1620, $\mathrm{p}=0,04)$, ролевое функционирование, обусловленное физическим состоянием РФФ (U=1552, $\mathrm{p}=0,02)$, общее состояние здоровья О3 ( $\mathrm{U}=1250$, $\mathrm{p}<0,0001)$, интенсивность боли Б $(\mathrm{U}=1357$, $\mathrm{p}=0,002)$, жизненная активность Ж $(\mathrm{U}=1194$, $\mathrm{p}=0,0001)$, психическое здоровье П3 (U=1398, $\mathrm{p}=0,003)$. В контрольной группе физический и психический компоненты здоровья в 1,2 раза выше по сравнению с пациентами после глазного протезирования, составили в среднем по физическому компоненту $56,64[52,48 ; 57,17]$ и $48,64[37,81 ; 53,75]$ и психическому компоненту $57,7[49,34 ; 60,52]$ и 48,09 [39,67; 55,47], соответственно (рис. 1).

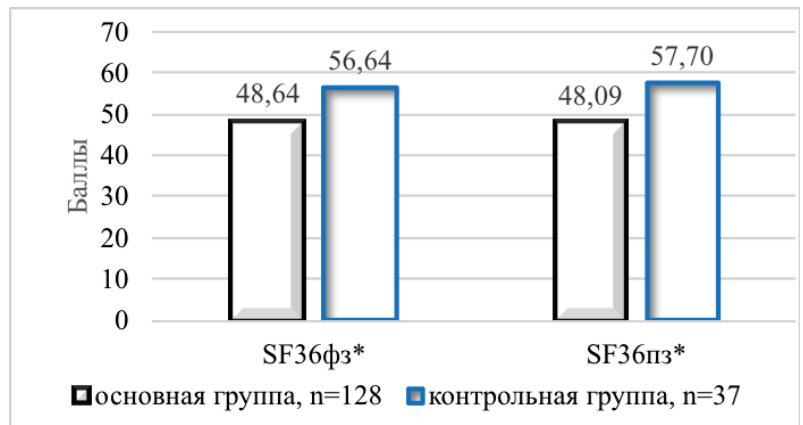

Рисунок 1. - Физический и психический компоненты здоровья у пациентов после глазного протезирования и в контрольной группе $\left({ }^{*}-p<0,001\right)$

При сравнении показателей КЖ по полу уровень КЖ у пациентов после глазного протезирования женского пола значимо снижен как по интегральным показателям психического (SF36пз), так и физического здоровья (SF36фз), в том числе и по их составляющим шкалам: физическое функционирование, жизненная активность, социальное функционирование, психическое здоровье, интенсивность боли (рис. 2).

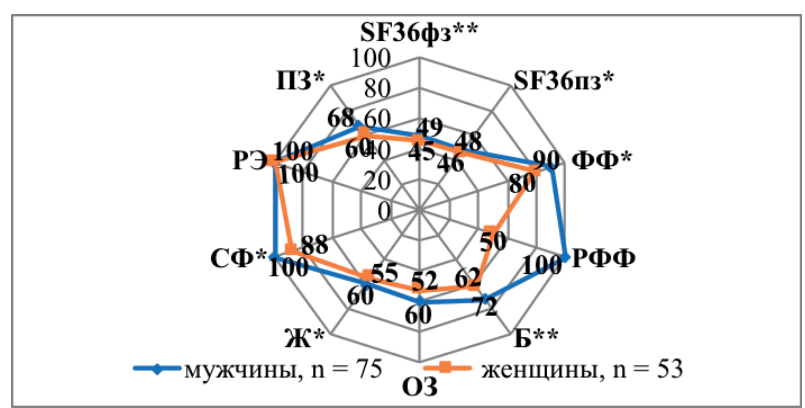

Рисунок 2. - Качество жизни пациентов мужского и женского пола после глазного протезирования (*-p<0,05, ** - р стремится к 0,05) 
Ношение глазного протеза у пациентов женского пола приводит к депрессивным и тревожным переживаниям, ограничению социальных контактов и физических нагрузок.

Показатели КЖ пациентов с анофтальмом после удаления глазного яблока по разработанному методу выше по всем шкалам по сравнению с пациентами с анофтальмом, оперированными по стандартным методам - без использования орбитальных имплантатов. При этом наиболее низкие значения у пациентов, оперированных по стандартным методам - без использования орбитальных имплантатов - определялись по шкале ролевое функционирование, обусловленное физическим состоянием (РФФ) - 25\%, жизненная активность (Ж) - 50\%, общее здоровье $(\mathrm{O} 3)$ - 50\%, интенсивность боли (Б) $-60 \%$, ролевое функционирование, обусловленное эмоциональным состоянием (РЭ) - 66,7 \%, психическое здоровье (ПЗ) - $62 \%$ (рис. 3 ).

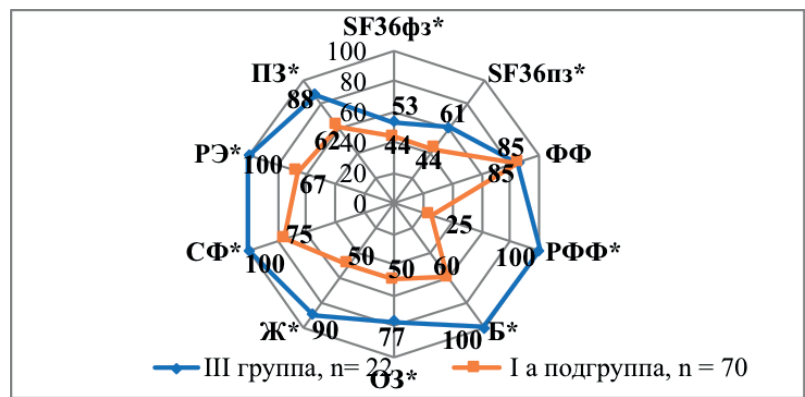

Рисунок 3. - Качество жизни пациентов с анофтальмом, оперированных по разработанному методу и по стандартному методу без использования орбитальных имплантатов (* - p<0,001)

Уровень КЖ у пациентов, оперированных по разработанному методу, также выше в сравнении с пациентами, оперированными по другим методам с использованием орбитальных имплантатов, особенно по шкалам психическое здоровье (ПЗ) - 60 \%, жизненная активность (Ж) - 65\%, общее здоровье (О3) - 55\% (рис. 4).

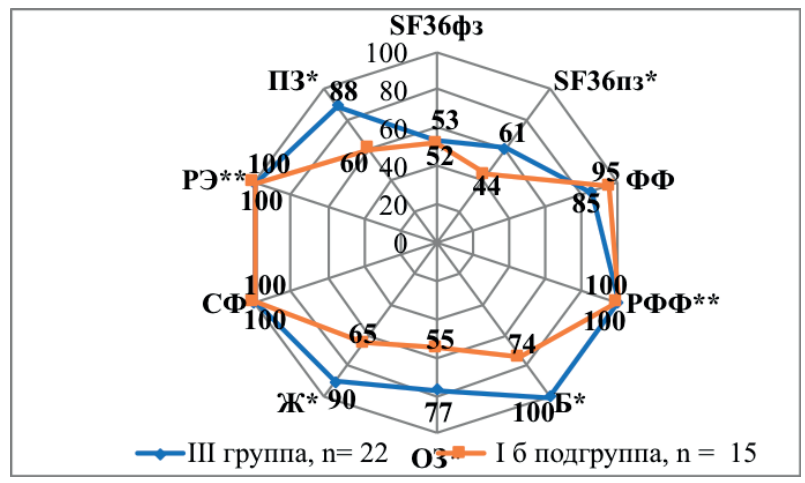

Рисунок 4. - Качество жизни пациентов, оперированных по разработанному методу и по стандартному методу с использованием орбитальных имплантатов $(*-p<0,05, * *-p$ стремится к 0,05)
КЖ пациентов с субатрофией глаза имеет низкие значения по шкалам ролевое функционирование, обусловленное эмоциональным состоянием (РЭ) - 33\%, интенсивность боли (Б) - 60\%, общее здоровье (О3) - 67\% (рис. 5).

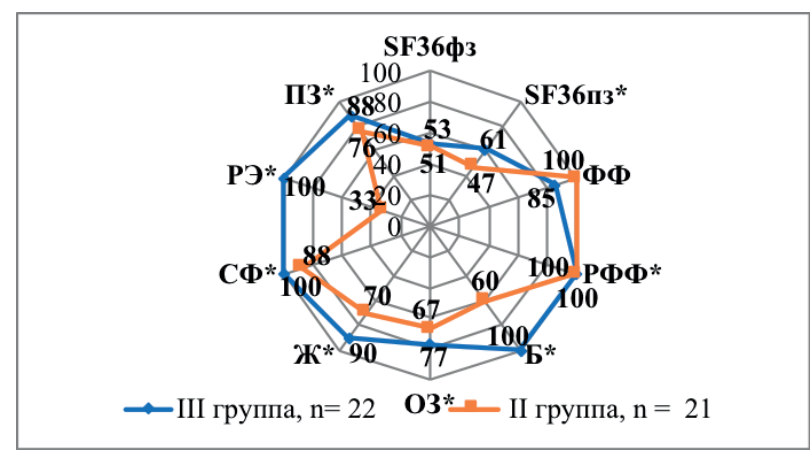

Рисунок 5. - Качество жсизни пациентов с анофтальмом, оперированных по разработанному методу, и пациентов с субатрофией глаза $(*-p<0,05)$

B III группе пациентов физический и психический компоненты здоровья были выше по сравнению с другими пациентами после глазного протезирования (рис. 6).

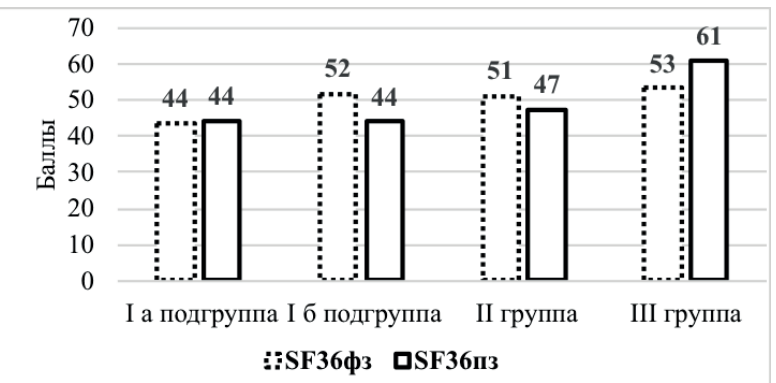

Рисунок 6. - Физический и психический компоненты здоровья среди пациентов после глазного протезирования (* $-p<0,001)$

При исследовании характера/вида причины, приведшей к потере зрения, среди пациентов основной группы значимых различий не выявлено, таким образом, причина заболевания не влияет на уровень КЖ.

Проведено также исследование по изучению КЖ пациентов до и после хирургии удаления глазного яблока по разработанному методу. Уровень КЖ значительно снижен у пациентов до операции как по интегральным показателям психического (SF36пз) и физического здоровья (SF36фз), так и по всем их составляющим шкалам. При этом наиболее низкие значения определялись по шкалам: ролевое функционирование, обусловленное физическим состоянием (РФФ) - 0 [0; 0], интенсивность боли (Б) - 41 [22; 41], жизненная активность (Ж) - 12,5 [10; $35]$, ролевое функционирование, обусловленное эмоциональным состоянием (РЭ) - 0 [0; 0], социальное функционирование (СФ) - 25 [13; 38], психическое здоровье (ПЗ) - 14 [8; 28] и общее здоровье (О3) - 35 [30; 45] (рис 7). 


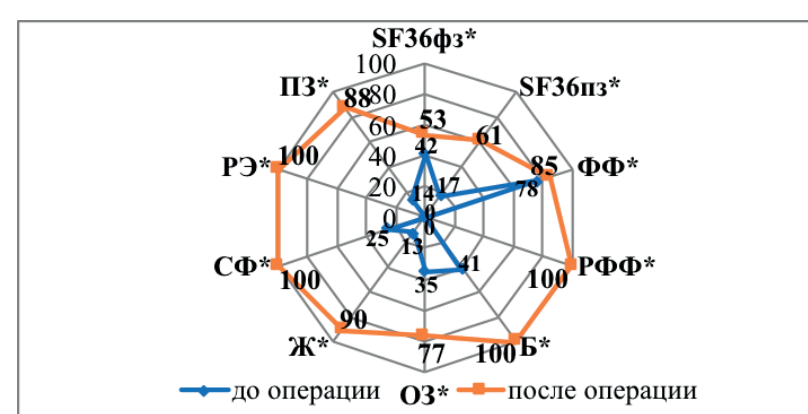

Рисунок 7. - Качество жизни пациентов до и после хирургии, оперированных по разработанному методу $(*-p<0,001)$

Таким образом, пациент в процессе лечения оценивает состояние своего здоровья плохим (потеря зрения), не видит его перспективы лечения (сохранения глаза как органа), вследствие чего чувствует себя обессиленным, выраженный болевой синдром, связанный с основным забо-

\section{Лuтература}

1. Филатова, И. А. Анофтальм. Патология и лечение / И. А. Филатова. - Москва, 2007. - 213 с.

2. Вериго, Е. Н. Принципы и методы реабилитации больных с глазной патологией / Е. Н. Вериго // Сборник научных трудов. - Москва, 1988. - С. 38-42.

3. Бараш А. Н. Медико-социальные проблемы при анофтальмическом синдроме / А. Н. Бараш, Т. М. Шаршакова, Г. Ф. Малиновский // Проблемы здоровья и экологии. -2015 . - № 2 (44). - С. 4-7.

4. Медико-социальные проблемы офтальмопротезирования / М. И. Разумовский [и др.] // Медико-социальная экспертиза и реабилитация. - 2014. -№ 2. - С. 50-53.

5. Бараш, А. Н. Европейский подход к проблеме анофтальма на примере мурфилдской глазной клиники / А. Н. Бараш // Современные подходы к продвижению здоровья : материалы VI Международной научно-практической конференции, Гомель, 13 окт. 2016 г. / Гомельский государственный медицинский университет ; редкол. А. Н. Лызиков [и др.]. - Гомель : ГомГМУ, 2016. - Вып. 6. - С. 7-10.

6. Калинина, Т. В. Качество жизни населения как важнейшая составляющая общественного здоровья / Т. В. Калинина // Медицина. - 2008. - № 4. - С. 7-9.

7. Способ формирования опорно-двигательной культи глазного протеза при эвисцерации : евразийский пат. EA 028706 / Г. Ф. Малиновский, А. Н. Бараш. - Опубл. 29.12.2017. $-4 \mathrm{c}$ леванием, ограничивает повседневную деятельность. Физическое, эмоциональное состояние пациента и интенсивность боли, связанные со снижением общего состояния здоровья, ограничивают его повседневную деятельность и социальную активность.

\section{Выводы}

Полученные результаты исследования подтверждают, что тяжелая офтальмопатология, приведшая к потере зрения и глаза как органа, является тяжелой психологической и физической травмой для человека и снижает уровень общего состояния здоровья, при этом снижая КЖ по всем сферам. Операция по разработанному методу с формированием опорно-двигательной культи с использованием орбитального имплантата, позволяющего восполнить недостающий объем глазничного органокомплекса, и последующее поэтапное глазное протезирование - обязательная мера медицинской и социальной реабилитации пациентов.

\section{References}

1. Filatova IA. Anoftalm. Patologija i lechenie [Anophthalmos. Pathology and treatment]. Moskva; 2007. 213 p. (Russian).

2. Verigo EN. Principy i metody reabilitacii bolnyh s glaznoj patologiej. In: Sbornik nauchnyh trudov. Moskva; 1988. p. 38-42. (Russian).

3. Barash AN, Sharshakova TM, Malinovskij GF. Medikosocialnye problemy pri anoftalmicheskom syndrome. Problemy zdorovja i jekologii. 2015;2(44):4-7. (Russian).

4. Razumovskij MI, Kozhushko LA, Razumovskaja AM, Gordievskaja EO, Kuzmina IE. Mediko-socialnye problemy oftalmoprotezirovanija. Mediko-socialnaja jekspertiza i reabilitacija. 2014;2:50-53. (Russian).

5. Barash AN. Evropejskij podhod k probleme anoftalma na primere murfildskoj glaznoj kliniki. In: Lyzikov AN, Sharshakova TM, Voropaev EV, eds. Sovremennye podhody $k$ prodvizheniju zdorovja. Materialy VI Mezhdunarodnoj nauchno-prakticheskoj konferencii, 2016 Okt 13; Gomel. Gomel: GomGMU; 2016. Iss. 6; p. 7-10. (Russian).

6. Kalinina TV. Kachestvo zhizni naselenija kak vazhnejshaja sostavljajushhaja obshhestvennogo zdorovja. Medicina. 2008;4:7-9. (Russian).

7. Malinovskij GF, Barash GF, inventors; Belarussian Academy of Postgraduate Study, assignee. Sposob formirovanija oporno-dvigatelnoj kulti glaznogo proteza pri jevisceracii. Evrazijskij pat. EA 028706, 2017 Dec 29. (Russian).

\title{
ASSESMENT OF QUALITY OF LIFE OF PATIENTS AFTER OCULAR PROSTHETICS
}

\author{
Barash A. N.
}

Educational Institution "Gomel State Medical University", Gomel, Belarus

Purpose: to estimate the influence of eye prosthetics on quality of life of patients with anophthalmos and eye subatrophy.

Material and methods: 128 patients, 75 men and 53 women, participated in the research. The average age of patients was 59 [48; 70] years. For the assessment of quality of life of patients after eye prosthetics the SF-36 questionnaire, adapted by the International Center for Quality of Life Research was used (St. Petersburg). 
Results: The research of the quality of life in patients after eye prosthetics and otherwise healthy individuals revealed low quality of life in patients after eye prosthetics both by the integrated indicators of mental (MH) and physical health (PH), and by their constituent scales: physical functioning - PF (U=1620, p=0.04), role-functioning caused by physical condition $-R P(U=1552, p=0.02)$, general health $-G H(U=1250, p<0.0001)$, vital activity $V$ ( $U=1689, p=0.008)$, mental health $-\mathrm{MH}(U=1398, p=0.003)$.

Conclusions: The received results of the research confirm that acute ophthalmic pathology which has led to loss of sight and an eye is a severe psychological and physical injury for the person; it reduces the level of general health, at the same time decreasing quality of life in all spheres.

Keywords: eye prosthetics, quality of life, anophthalmos, eye subatrophy.

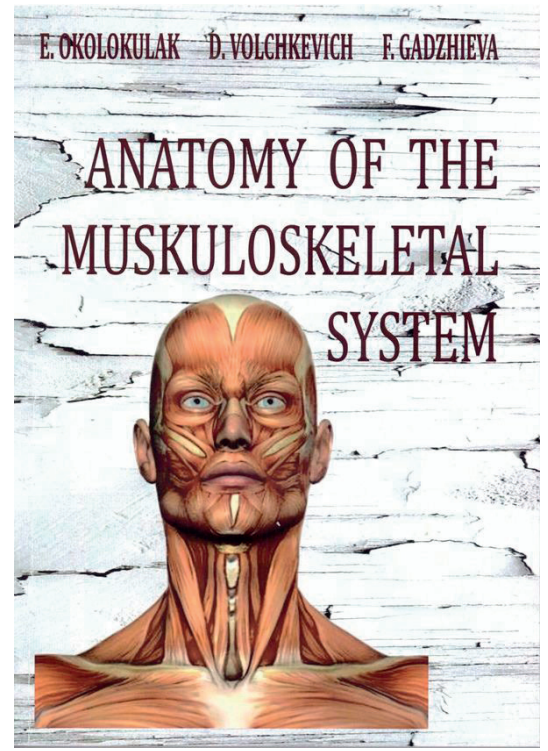

\section{Околокулак, Евгений Станиславович.}

Анатомия опорно-двигательной системы : учебное пособие для иностранных студентов [английский язык обучения] учреждений высшего образования по медицинским специальностям : допущено Министерством образования Республики Беларусь = Anatomy of the muskuloskeletal system : manual for medical students (in English) / Е. С. Околокулак, Д. А. Волчкевич, Ф. Г. Гаджиева ; Министерство здравоохранения Республики Беларусь, Учреждение образования "Гродненский государственный медицинский университет", Кафедра нормальной анатомии. - 2-е изд., стереотип. Гродно : ГрГМУ, 2018. - 287 р. : рис., табл. - Библиогр.: с. 287. - ISBN 978-985-595-051-7.

Данное пособие создано для студентов факультета иностранных, учашихся для раскрытия анатомии опорно-двигательного аппарата. Пособие освещяает вопросы строения, классификации и функции костей, суставов и мыпи. В структуру пособия включены тесты для самоконтроля студентов. 